\title{
Convergence analysis of an iterative algorithm for monotone operators
}

\author{
Sun Young $\mathrm{Cho}^{1}$, Wenling $\mathrm{Li}^{2}$ and Shin Min Kang ${ }^{3 *}$
}

"Correspondence: smkang@gnu.ac.kr

${ }^{3}$ Department of Mathematics and RINS, Gyeongsang National

University, Jinju, 660-701, Korea Full list of author information is available at the end of the article

\begin{abstract}
In this paper, an iterative algorithm is proposed to study some nonlinear operators which are inverse-strongly monotone, maximal monotone, and strictly pseudocontractive. Strong convergence of the proposed iterative algorithm is obtained in the framework of Hilbert spaces.
\end{abstract}

MSC: $47 \mathrm{H} 05 ; 47 \mathrm{H} 09$

Keywords: inverse-strongly monotone mapping; maximal monotone operator; resolvent; strictly pseudocontractive mapping; fixed point

\section{Introduction}

Splitting methods have recently received much attention due to the fact that many nonlinear problems arising in applied areas such as image recovery, signal processing, and machine learning are mathematically modeled as a nonlinear operator equation, and this operator is decomposed as the sum of two nonlinear operators. Study of fixed (zero) point approximation algorithms for computing fixed (zero) points constitutes now a topic of intensive research efforts. Many well-known problems can be studied by using algorithms which are iterative in their nature. As an example, in computer tomography with limited data, each piece of information implies the existence of a convex set in which the required solution lies. The problem of finding a point in the intersection of these convex sets is then of crucial interest, and it cannot be usually solved directly. Therefore, an iterative algorithm must be used to approximate such a point. The well-known convex feasibility problem which captures applications in various disciplines such as image restoration and radiation therapy treatment planning is to find a point in the intersection of common fixed (zero) point sets of a family of nonlinear mappings; see, for example, [1-16].

In this paper, we will investigate the problem of finding a common solution to inclusion problems and fixed point problems based on an iterative algorithm. Strong convergence of the proposed iterative algorithm has been obtained in the framework of Hilbert spaces.

The organization of this paper is as follows. In Section 2, we provide some necessary preliminaries. In Section 3, an iterative algorithm is proposed and analyzed. Some subresults of the main results are also discussed in this section.

\section{Preliminaries}

From now on, we always assume that $H$ is a real Hilbert space with the inner product $\langle\cdot, \cdot\rangle$ and the norm $\|\cdot\|$, respectively. Let $C$ be a nonempty closed convex subset of $H$.

(c) 2013 Cho et al.; licensee Springer. This is an Open Access article distributed under the terms of the Creative Commons Attribution License (http://creativecommons.org/licenses/by/2.0), which permits unrestricted use, distribution, and reproduction in any medium, provided the original work is properly cited. 
Let $S: C \rightarrow C$ be a mapping. $F(S)$ stands for the fixed point set of $S$; that is, $F(S):=\{x \in$ $C: x=S x\}$.

Recall that $S$ is said to be nonexpansive iff

$$
\|S x-S y\| \leq\|x-y\|, \quad \forall x, y \in C .
$$

$S$ is said to be asymptotically nonexpansive iff there exists a sequence $\left\{k_{n}\right\} \subset[1, \infty)$ with $\lim _{n \rightarrow \infty} k_{n}=1$ such that

$$
\left\|S^{n} x-S^{n} y\right\| \leq k_{n}\|x-y\|, \quad \forall x, y \in C .
$$

Recall that $S$ is said to be strictly pseudocontractive iff there exits a positive constant $\kappa$ such that

$$
\|S x-S y\|^{2} \leq\|x-y\|^{2}+\kappa\|(x-S x)-(y-S y)\|^{2}, \quad \forall x, y \in C .
$$

$S$ is said to be asymptotically strictly pseudocontractive iff there exits a positive constant $\kappa$ and a sequence $\left\{k_{n}\right\} \subset[1, \infty)$ with $\lim _{n \rightarrow \infty} k_{n}=1$ such that

$$
\left\|S^{n} x-S^{n} y\right\|^{2} \leq k_{n}\|x-y\|^{2}+\kappa\left\|\left(x-S^{n} x\right)-\left(y-S^{n} y\right)\right\|^{2}, \quad \forall x, y \in C .
$$

Let $A: C \rightarrow H$ be a mapping. Recall that $A$ is said to be monotone iff

$$
\langle A x-A y, x-y\rangle \geq 0, \quad \forall x, y \in C .
$$

$A$ is said to be inverse-strongly monotone iff there exists a constant $\alpha>0$ such that

$$
\langle A x-A y, x-y\rangle \geq \alpha\|A x-A y\|^{2}, \quad \forall x, y \in C .
$$

For such a case, $A$ is also said to be $\alpha$-inverse-strongly monotone. It is not hard to see that inverse-strongly monotone mappings are Lipschitz continuous.

A multivalued operator $T: H \rightarrow 2^{H}$ with the domain $D(T)=\{x \in H: T x \neq \emptyset\}$ and the range $R(T)=\{T x: x \in D(T)\}$ is said to be monotone if for $x_{1} \in D(T), x_{2} \in D(T), y_{1} \in T x_{1}$ and $y_{2} \in T x_{2}$, we have $\left\langle x_{1}-x_{2}, y_{1}-y_{2}\right\rangle \geq 0$. A monotone operator $T$ is said to be maximal if its graph $G(T)=\{(x, y): y \in T x\}$ is not properly contained in the graph of any other monotone operator. Let $I$ denote the identity operator on $H$ and $T: H \rightarrow 2^{H}$ be a maximal monotone operator. Then we can define, for each $\lambda>0$, a nonexpansive single-valued mapping $J_{\lambda}: H \rightarrow H$ by $J_{\lambda}=(I+\lambda T)^{-1}$. It is called the resolvent of $T$. We know that $T^{-1} 0=$ $F\left(J_{\lambda}\right)$ for all $\lambda>0$ and $J_{\lambda}$ is firmly nonexpansive; see [17-23] and the references therein.

Recently, many authors have investigated the solution problems of nonlinear operator equations or inequalities based on iterative methods; see, for instance, [24-33] and the references therein. In [19], Kamimura and Takahashi investigated the problem of finding zero points of a maximal monotone operator via the following iterative algorithm:

$$
x_{0} \in H, \quad x_{n+1}=\alpha_{n} x_{n}+\left(1-\alpha_{n}\right) J_{\lambda_{n}} x_{n}, \quad n=0,1,2, \ldots,
$$


where $\left\{\alpha_{n}\right\}$ is a sequence in $(0,1),\left\{\lambda_{n}\right\}$ is a positive sequence, $T: H \rightarrow 2^{H}$ is a maximal monotone and $J_{\lambda_{n}}=\left(I+\lambda_{n} T\right)^{-1}$. They showed that the sequence $\left\{x_{n}\right\}$ generated in (2.1) converges weakly to some $z \in T^{-1}(0)$ provided that the control sequence satisfies some restrictions.

Recall that the classical variational inequality is to find an $x \in C$ such that

$$
\langle A x, y-x\rangle \geq 0, \quad \forall y \in C
$$

In this paper, we use $\operatorname{VI}(C, A)$ to denote the solution set of (2.2). It is known that $x \in C$ is a solution to (2.1) iff $x$ is a fixed point of the mapping $P_{C}(I-\lambda A)$, where $\lambda>0$ is a constant, $I$ stands for the identity mapping, and $P_{C}$ stands for the metric projection from $H$ onto $C$. If $A$ is $\alpha$-inverse-strongly monotone and $\lambda \in(0,2 \alpha]$, then the mapping $P_{C}(I-r A)$ is nonexpansive; see [28] for more details. It follows that $\operatorname{VI}(C, A)$ is closed and convex.

In [28], Takahashi an Toyoda investigated the problem of finding a common solution of variational inequality problem (2.1) and a fixed point problem involving nonexpansive mappings by considering the following iterative algorithm:

$$
x_{0} \in C, \quad x_{n+1}=\alpha_{n} x_{n}+\left(1-\alpha_{n}\right) S P_{C}\left(x_{n}-\lambda_{n} A x_{n}\right), \quad \forall n \geq 0,
$$

where $\left\{\alpha_{n}\right\}$ is a sequence in $(0,1),\left\{\lambda_{n}\right\}$ is a positive sequence, $S: C \rightarrow C$ is a nonexpansive mapping and $A: C \rightarrow H$ is an inverse-strongly monotone mapping. They proved that the sequence $\left\{x_{n}\right\}$ generated in (2.3) converges weakly to some $z \in \mathrm{VI}(C, A) \cap F(S)$ provided that the control sequence satisfies some restrictions.

In [29], Tada and Takahashi investigated the problem of finding a common solution of an equilibrium problem and a fixed point problem involving nonexpansive mappings by considering the following iterative algorithm:

$$
\left\{\begin{array}{l}
u_{n} \in C \quad \text { such that } F\left(u_{n}, u\right)+\frac{1}{r_{n}}\left\langle u-u_{n}, u_{n}-x_{n}\right\rangle \geq 0, \quad \forall u \in C, \\
x_{n+1}=\alpha_{n} x_{n}+\left(1-\alpha_{n}\right) S u_{n}
\end{array}\right.
$$

for each $n \geq 1$, where $\left\{\alpha_{n}\right\}$ is a sequence in $(0,1),\left\{r_{n}\right\}$ is a positive sequence, $S: C \rightarrow C$ is a nonexpansive mapping and $F: C \times C \rightarrow R$ is a bifunction. They showed that the sequence $\left\{x_{n}\right\}$ generated in (2.4) converges weakly to some $z \in \operatorname{EP}(F) \cap F(S)$, where $\operatorname{EP}(F)$ stands for the solution set of the equilibrium problem, provided that the control sequence satisfies some restrictions.

In [30], Manaka and Takahashi introduced the following iteration:

$$
x_{1} \in C, \quad x_{n+1}=\alpha_{n} x_{n}+\left(1-\alpha_{n}\right) S J_{\lambda_{n}}\left(I-\lambda_{n} A\right) x_{n}, \quad n \geq 1,
$$

where $\left\{\alpha_{n}\right\}$ is a sequence in $(0,1),\left\{\lambda_{n}\right\}$ is a positive sequence, $S: C \rightarrow C$ is a nonexpansive mapping, $A: C \rightarrow H$ is an inversely-strongly monotone mapping, $B: D(B) \subset C \rightarrow 2^{H}$ is a maximal monotone operator, $J_{\lambda_{n}}=\left(I+\lambda_{n} B\right)^{-1}$ is the resolvent of $B$. They showed that the sequence $\left\{x_{n}\right\}$ generated in (2.5) converges weakly to some $z \in(A+B)^{-1}(0) \cap F(S)$ provided that the control sequence satisfies some restrictions.

In this paper, motivated by the above results, we consider the problem of finding a common solution to the zero point problems involving two monotone operators and fixed 
point problems involving asymptotically strictly pseudocontractive mappings based on a one-step iterative method. Weak convergence theorems are established in the framework of Hilbert spaces.

In order to obtain our main results in this paper, we need the following lemmas.

Recall that a space is said to satisfy Opial's property [34] if, for any sequence $\left\{x_{n}\right\} \subset H$ with $x_{n} \rightarrow x$, where $\rightarrow$ denotes the weak convergence, the inequality

$$
\liminf _{n \rightarrow \infty}\left\|x_{n}-x\right\|<\liminf _{n \rightarrow \infty}\left\|x_{n}-y\right\|
$$

holds for every $y \in H$ with $y \neq x$. Indeed, the above inequality is equivalent to the following:

$$
\limsup _{n \rightarrow \infty}\left\|x_{n}-x\right\|<\limsup _{n \rightarrow \infty}\left\|x_{n}-y\right\|
$$

Lemma 2.1 [20] Let $C$ be a nonempty, closed, and convex subset of $H, A: C \rightarrow H$ be a mapping, and $B: H \rightrightarrows H$ be a maximal monotone operator. Then $F\left(J_{r}(I-\lambda A)\right)=(A+$ $B)^{-1}(0)$.

Lemma 2.2 Let $H$ be a real Hilbert space. For any $a \in(0,1)$ and $x, y \in H$, the following holds:

$$
\|a x+(1-a) y\|^{2}=a\|x\|^{2}+(1-a)\|y\|^{2}-a(1-a)\|x-y\|^{2} .
$$

Lemma 2.3 [35] Let $\left\{a_{n}\right\},\left\{b_{n}\right\}$, and $\left\{c_{n}\right\}$ be three nonnegative sequences satisfying the following condition:

$$
a_{n+1} \leq\left(1+b_{n}\right) a_{n}+c_{n}, \quad \forall n \geq n_{0},
$$

where $n_{0}$ is some nonnegative integer, $\sum_{n=1}^{\infty} b_{n}<\infty$ and $\sum_{n=1}^{\infty} c_{n}<\infty$. Then the limit $\lim _{n \rightarrow \infty} a_{n}$ exists.

Lemma 2.4 [36] Let C be a nonempty closed convex subset of $H$ and $S$ be an asymptotically $\kappa$-strictly pseudocontractive mapping. Then we have

(a) S is uniformly Lipschitz continuous;

(b) $I-S$ is demiclosed at zero, that is, if $\left\{x_{n}\right\}$ is a sequence in $C$ with $x_{n} \rightarrow x$ and $x_{n}-S x_{n} \rightarrow 0$, then $x \in F(S)$.

The following lemma can be obtained from [37] immediately.

Lemma 2.5 Let $H$ be a real Hilbert space. The following holds:

$$
\left\|\sum_{i=1}^{N} a_{i} x_{i}\right\|^{2}=\sum_{i=1}^{N} a_{i}\left\|x_{i}\right\|^{2}-\sum_{i \neq j}^{N} a_{i} a_{j}\left\|x_{i}-x_{j}\right\|^{2},
$$

where $N \geq 2$ denotes some positive integer, $a_{1}, a_{2}, \ldots, a_{N}$ are real numbers with $\sum_{i=1}^{N} a_{i}=1$ in $(0,1)$ and $x_{1}, x_{2}, \ldots, x_{N} \in H$. 


\section{Main results}

Theorem 3.1 Let $C$ be a nonempty closed convex subset of $H$. Let $N \geq 2$ be some positive integer and $S: C \rightarrow C$ be an asymptotically strictly pseudocontractive mapping with the constant $\kappa$ and the sequence $\left\{k_{n}\right\}$. Let $A_{m}: C \rightarrow H$ be an inverse-strongly monotone mapping with the constant $\alpha_{m}$ and $B_{m}$ be a maximal monotone operator on $H$ such that the domain of $B_{m}$ is included in $C$ for each $m \in\{2,3, \ldots, N\}$. Assume $\mathcal{F}=\bigcap_{m=2}^{N}\left(A_{m}+B_{m}\right)^{-1}(0) \cap$ $F(S) \neq \emptyset$. Let $\left\{\alpha_{n, 1}\right\},\left\{\alpha_{n, 2}\right\}, \ldots,\left\{\alpha_{n, N}\right\}$ and $\left\{\beta_{n}\right\}$ are real number sequences in $(0,1)$. Let $\left\{r_{n, 2}\right\}, \ldots$, and $\left\{r_{n, N}\right\}$ be positive real number sequences. Let $\left\{x_{n}\right\}$ be a sequence in $C$ generated in the following iterative process:

$$
\left\{\begin{array}{l}
x_{1} \in C, \\
y_{n}=\beta_{n} x_{n}+\left(1-\beta_{n}\right) S^{n} x_{n}, \\
x_{n+1}=\alpha_{n, 1} y_{n}+\sum_{m=2}^{N} \alpha_{n, m} J_{r_{n, m}}\left(x_{n}-r_{n, m} A_{m} x_{n}\right), \quad n \geq 1,
\end{array}\right.
$$

where $J_{r_{n, m}}=\left(I+r_{n, m} B_{m}\right)^{-1}$ is the resolvent of $B_{m}$. Assume that the sequences $\left\{\alpha_{n, 1}\right\},\left\{\alpha_{n, 2}\right\}, \ldots$, $\left\{\alpha_{n, N}\right\},\left\{\beta_{n}\right\},\left\{r_{n, 2}\right\}, \ldots,\left\{r_{n, N}\right\}$, and $\left\{k_{n}\right\}$ satisfy the following restrictions:

(a) $\sum_{m=1}^{N} \alpha_{n, m}=1$ and $0<a \leq \alpha_{n, m}<1, \forall m \in\{2, \ldots, N\}$;

(b) $0 \leq \kappa \leq \beta_{n} \leq b<1$;

(c) $0<c \leq r_{n, m} \leq d<2 \alpha_{m}, \forall m \in\{2, \ldots, N\}$;

(d) $\sum_{n=1}^{\infty}\left(k_{n}-1\right)<\infty$,

where $a, b, c$, and $d$ are positive real numbers. Then the sequence $\left\{x_{n}\right\}$ generated in (3.1) converges weakly to some point in $\mathcal{F}$.

Proof First, we show $I-r_{n, m} A_{m}$ is nonexpansive. In view of the restriction (c), we find that

$$
\begin{aligned}
& \left\|\left(I-r_{n, m} A_{m}\right) x-\left(I-r_{n, m} A_{m}\right) y\right\|^{2} \\
& \quad=\|x-y\|^{2}-2 r_{n, m}\left\langle x-y, A_{m} x-A_{m} y\right\rangle+r_{n, m}^{2}\left\|A_{m} x-A_{m} y\right\|^{2} \\
& \quad \leq\|x-y\|^{2}-r_{n, m}\left(2 \alpha_{m}-r_{n, m}\right)\left\|A_{m} x-A_{m} y\right\|^{2} \\
& \quad \leq\|x-y\|^{2} .
\end{aligned}
$$

This proves that $I-r_{n, m} A_{m}$ is nonexpansive. Let $p \in \mathcal{F}$. In view of Lemma 2.1, we find that

$$
p=S p=J_{r_{n, m}}\left(p-r_{n, m} A_{m} p\right) .
$$

Putting $u_{n, m}=J_{r_{n, m}}\left(x_{n}-r_{n, m} A_{m} x_{n}\right)$, we find that

$$
\begin{aligned}
\left\|u_{n, m}-p\right\| & \leq\left\|\left(x_{n}-r_{n, m} A_{m} x_{n}\right)-\left(p-r_{n, m} A_{m} p\right)\right\| \\
& \leq\left\|x_{n}-p\right\| .
\end{aligned}
$$

In view of Lemma 2.2, we find from the restriction (b) that

$$
\begin{aligned}
\left\|y_{n}-p\right\|^{2} & =\left\|\beta_{n} x_{n}+\left(1-\beta_{n}\right) S^{n} x_{n}-p\right\|^{2} \\
& =\beta_{n}\left\|x_{n}-p\right\|^{2}+\left(1-\beta_{n}\right)\left\|S^{n} x_{n}-p\right\|^{2}-\beta_{n}\left(1-\beta_{n}\right)\left\|x_{n}-S^{n} x_{n}\right\|^{2}
\end{aligned}
$$




$$
\begin{aligned}
& \leq \beta_{n}\left\|x_{n}-p\right\|^{2}+\left(1-\beta_{n}\right) k_{n}\left\|x_{n}-p\right\|^{2}+\left(\kappa-\beta_{n}\right)\left\|x_{n}-S^{n} x_{n}\right\|^{2} \\
& \leq k_{n}\left\|x_{n}-p\right\|^{2} .
\end{aligned}
$$

From (3.2) and (3.3), we have

$$
\begin{aligned}
\left\|x_{n+1}-p\right\|^{2} & =\left\|\alpha_{n, 1}\left(y_{n}-p\right)+\sum_{m=2}^{N} \alpha_{n, m}\left(u_{n, m}-p\right)\right\|^{2} \\
& \leq \alpha_{n, 1}\left\|y_{n}-p\right\|^{2}+\sum_{m=2}^{N} \alpha_{n, m}\left\|u_{n, m}-p\right\|^{2} \\
& \leq \alpha_{n, 1} k_{n}\left\|x_{n}-p\right\|^{2}+\sum_{m=2}^{N} \alpha_{n, m}\left\|x_{n}-p\right\|^{2} \\
& \leq k_{n}\left\|x_{n}-p\right\|^{2} .
\end{aligned}
$$

We draw the conclusion that $\lim _{n \rightarrow \infty}\left\|x_{n}-p\right\|$ exists with the aid of Lemma 2.3. This implies that the sequence $\left\{x_{n}\right\}$ is bounded. In view of Lemma 2.5, we find that

$$
\begin{aligned}
\left\|x_{n+1}-p\right\|^{2}= & \left\|\alpha_{n, 1}\left(y_{n}-p\right)+\sum_{m=2}^{N} \alpha_{n, m}\left(u_{n, m}-p\right)\right\|^{2} \\
\leq & \alpha_{n, 1}\left\|y_{n}-p\right\|^{2}+\sum_{m=2}^{N} \alpha_{n, m}\left\|u_{n, m}-p\right\|^{2} \\
& -\alpha_{n, 1} \alpha_{n, r}\left\|y_{n}-u_{n, r}\right\|^{2} \\
\leq & \alpha_{n, 1} k_{n}\left\|x_{n}-p\right\|^{2}+\sum_{m=2}^{N} \alpha_{n, m}\left\|x_{n}-p\right\|^{2} \\
& -\alpha_{n, 1} \alpha_{n, r}\left\|y_{n}-u_{n, r}\right\|^{2} \\
\leq & k_{n}\left\|x_{n}-p\right\|^{2}-\alpha_{n, 1} \alpha_{n, r}\left\|y_{n}-u_{n, r}\right\|^{2}, \quad \forall r \in\{2,3, \ldots, N\},
\end{aligned}
$$

which yields

$$
\alpha_{n, 1} \alpha_{n, r}\left\|y_{n}-u_{n, r}\right\|^{2} \leq k_{n}\left\|x_{n}-p\right\|^{2}-\left\|x_{n+1}-p\right\|^{2}, \quad \forall r \in\{2,3, \ldots, N\}
$$

In view of the restriction (a), we find that

$$
\lim _{n \rightarrow \infty}\left\|y_{n}-u_{n, m}\right\|=0, \quad \forall r \in\{2,3, \ldots, N\}
$$

On the other hand, we have

$$
\begin{aligned}
\left\|u_{n, m}-p\right\|^{2} & \leq\left\|\left(x_{n}-r_{n, m} A_{m} x_{n}\right)-\left(p-r_{n, m} A_{m} p\right)\right\|^{2} \\
& =\left\|x_{n}-p\right\|^{2}-2 r_{n, m}\left\langle x_{n}-p, A_{m} x_{n}-A_{m} p\right\rangle+r_{n, m}^{2}\left\|A_{m} x_{n}-A_{m} p\right\|^{2} \\
& \leq\left\|x_{n}-p\right\|^{2}-r_{n, m}\left(2 \alpha_{m}-r_{n, m}\right)\left\|A_{m} x_{n}-A_{m} p\right\|^{2} .
\end{aligned}
$$


It follows that

$$
\begin{aligned}
\left\|x_{n+1}-p\right\|^{2} & \leq \alpha_{n, 1}\left\|y_{n}-p\right\|^{2}+\sum_{m=2}^{N} \alpha_{n, m}\left\|u_{n, m}-p\right\|^{2} \\
& \leq \alpha_{n, 1} k_{n}\left\|x_{n}-p\right\|^{2}+\sum_{m=2}^{N} \alpha_{n, m}\left\|u_{n, m}-p\right\|^{2} \\
& \leq k_{n}\left\|x_{n}-p\right\|^{2}-\sum_{m=2}^{N} \alpha_{n, m} r_{n, m}\left(2 \alpha_{m}-r_{n, m}\right)\left\|A_{m} x_{n}-A_{m} p\right\|^{2} .
\end{aligned}
$$

This in turn implies that

$$
\sum_{m=2}^{N} \alpha_{n, m} r_{n, m}\left(2 \alpha_{m}-r_{n, m}\right)\left\|A_{m} x_{n}-A_{m} p\right\|^{2} \leq k_{n}\left\|x_{n}-p\right\|^{2}-\left\|x_{n+1}-p\right\|^{2} .
$$

It follows from the restrictions (b) and (d) that

$$
\lim _{n \rightarrow \infty}\left\|A_{m} x_{n}-A_{m} p\right\|=0 .
$$

Notice that

$$
\begin{aligned}
\left\|u_{n, m}-p\right\|^{2} \leq & \left\langle\left(x_{n}-r_{n, m} A_{m} x_{n}\right)-\left(p-r_{n, m} A_{m} p\right), u_{n, m}-p\right\rangle \\
= & \frac{1}{2}\left(\left\|\left(x_{n}-r_{n} A_{m} x_{n}\right)-\left(p-r_{n} A_{m} p\right)\right\|^{2}+\left\|u_{n, m}-p\right\|^{2}\right. \\
& \left.-\left\|\left(x_{n}-r_{n} A_{m} x_{n}\right)-\left(p-r_{n} A_{m} p\right)-\left(u_{n, m}-p\right)\right\|^{2}\right) \\
\leq & \frac{1}{2}\left(\left\|x_{n}-p\right\|^{2}+\left\|u_{n, m}-p\right\|^{2}-\left\|x_{n}-u_{n, m}-r_{n}\left(A_{m} x_{n}-A_{m} p\right)\right\|^{2}\right) \\
\leq & \frac{1}{2}\left(\left\|x_{n}-p\right\|^{2}+\left\|u_{n, m}-p\right\|^{2}-\left\|x_{n}-u_{n, m}\right\|^{2}-r_{n}^{2}\left\|A_{m} x_{n}-A_{m} p\right\|^{2}\right. \\
& \left.+2 r_{n}\left\|x_{n}-u_{n, m}\right\|\left\|A_{m} x_{n}-A_{m} p\right\|\right) \\
\leq & \frac{1}{2}\left(\left\|x_{n}-p\right\|^{2}+\left\|u_{n, m}-p\right\|^{2}-\left\|x_{n}-u_{n, m}\right\|^{2}\right. \\
& \left.+2 r_{n}\left\|x_{n}-u_{n, m}\right\|\left\|A_{m} x_{n}-A_{m} p\right\|\right) .
\end{aligned}
$$

It follows that

$$
\left\|u_{n, m}-p\right\|^{2} \leq\left\|x_{n}-p\right\|^{2}-\left\|x_{n}-u_{n, m}\right\|^{2}+2 r_{n, m}\left\|x_{n}-u_{n, m}\right\|\left\|A_{m} x_{n}-A_{m} p\right\| .
$$

This implies that

$$
\begin{aligned}
\left\|x_{n+1}-p\right\|^{2} & =\left\|\alpha_{n, 1}\left(y_{n}-p\right)+\sum_{m=2}^{N} \alpha_{n, m}\left(u_{n, m}-p\right)\right\|^{2} \\
& \leq \alpha_{n, 1}\left\|y_{n}-p\right\|^{2}+\sum_{m=2}^{N} \alpha_{n, m}\left\|u_{n, m}-p\right\|^{2}
\end{aligned}
$$




$$
\begin{aligned}
\leq & k_{n}\left\|x_{n}-p\right\|^{2}-\sum_{m=2}^{N} \alpha_{n, m}\left\|x_{n}-u_{n, m}\right\|^{2} \\
& +2 \sum_{m=2}^{N} \alpha_{n, m} r_{n, m}\left\|x_{n}-u_{n, m}\right\|\left\|A_{m} x_{n}-A_{m} p\right\|,
\end{aligned}
$$

which finds that

$$
\begin{aligned}
\sum_{m=2}^{N} \alpha_{n, m}\left\|x_{n}-u_{n, m}\right\|^{2} \leq & k_{n}\left\|x_{n}-p\right\|^{2}-\left\|x_{n+1}-p\right\|^{2} \\
& +2 \sum_{m=2}^{N} \alpha_{n, m} r_{n, m}\left\|x_{n}-u_{n, m}\right\|\left\|A_{m} x_{n}-A_{m} p\right\| .
\end{aligned}
$$

In view of the restriction (a), we find from (3.8) that

$$
\lim _{n \rightarrow \infty}\left\|x_{n}-u_{n, m}\right\|=0
$$

Notice that

$$
\left\|x_{n}-y_{n}\right\| \leq\left\|x_{n}-u_{n, m}\right\|+\left\|u_{n, m}-y_{n}\right\| .
$$

From (3.6) and (3.10), we obtain that

$$
\lim _{n \rightarrow \infty}\left\|x_{n}-y_{n}\right\|=0 \text {. }
$$

On the other hand, we have

$$
\begin{aligned}
\left\|S^{n} x_{n}-x_{n}\right\| & \leq\left\|S^{n} x_{n}-\left(\beta_{n} x_{n}+\left(1-\beta_{n}\right) S^{n} x_{n}\right)\right\|+\left\|\left(\beta_{n} x_{n}+\left(1-\beta_{n}\right) S^{n} x_{n}\right)-x_{n}\right\| \\
& =\beta_{n}\left\|S^{n} x_{n}-x_{n}\right\|+\left\|y_{n}-x_{n}\right\|,
\end{aligned}
$$

which yields

$$
\left(1-\beta_{n}\right)\left\|S^{n} x_{n}-x_{n}\right\| \leq\left\|y_{n}-x_{n}\right\|
$$

This implies from the restriction (c) and (3.11) that

$$
\lim _{n \rightarrow \infty}\left\|S^{n} x_{n}-x_{n}\right\|=0
$$

Notice that

$$
\left\|x_{n+1}-x_{n}\right\| \leq \alpha_{n, 1}\left\|y_{n}-x_{n}\right\|+\sum_{m=2}^{N} \alpha_{n, m}\left\|u_{n, m}-x_{n}\right\| .
$$

This implies from (3.10) and (3.11) that

$$
\lim _{n \rightarrow \infty}\left\|x_{n+1}-x_{n}\right\|=0
$$


On the other hand, we have

$$
\begin{aligned}
\left\|x_{n}-S x_{n}\right\| \leq & \left\|x_{n}-x_{n+1}\right\|+\left\|x_{n+1}-S^{n+1} x_{n+1}\right\| \\
& +\left\|S^{n+1} x_{n+1}-S^{n+1} x_{n}\right\|+\left\|S^{n+1} x_{n}-S x_{n}\right\| .
\end{aligned}
$$

Since $S$ is uniformly continuous, we obtain from (3.12) and (3.13) that

$$
\lim _{n \rightarrow \infty}\left\|S x_{n}-x_{n}\right\|=0
$$

Since $\left\{x_{n}\right\}$ is bounded, there exists a subsequence $\left\{x_{n_{i}}\right\}$ of $\left\{x_{n}\right\}$ such that $x_{n_{i}} \rightarrow \omega \in C$. We find that $\omega \in F(S)$ with the aid of Lemma 2.4.

Next, we show $\omega \in\left(A_{m}+B_{m}\right)^{-1} 0$ for every $m \in\{1,2, \ldots, N\}$. In view of (3.10), we can choose a subsequence $\left\{u_{n_{i}, m}\right\}$ of $\left\{u_{n, m}\right\}$ such that $u_{n_{i}, m} \rightarrow \omega$. Notice that

$$
u_{n, m}=J_{r_{n, m}}\left(x_{n}-r_{n, m} A_{m} x_{n}\right) .
$$

This implies that

$$
x_{n}-r_{n, m} A_{m} x_{n} \in\left(I+r_{n, m} B_{m}\right) u_{n, m} .
$$

That is,

$$
\frac{x_{n}-u_{n, m}}{r_{n, m}}-A_{m} x_{n} \in B_{m} u_{n, m} .
$$

Since $B_{m}$ is monotone, we get for any $\left(u_{m}, v_{m}\right) \in G\left(B_{m}\right)$ that

$$
\left\langle u_{n, m}-u_{m}, \frac{x_{n}-u_{n, m}}{r_{n, m}}-A_{m} x_{n}-v_{m}\right\rangle \geq 0 .
$$

Replacing $n$ by $n_{i}$ and letting $i \rightarrow \infty$, we obtain from (3.10) that

$$
\left\langle\omega-u_{m},-A_{m} \omega-v_{m}\right\rangle \leq 0 .
$$

This means $-A_{m} \omega_{m} \in B_{m} \omega$, that is, $0 \in\left(A_{m}+B_{m}\right)(\omega)$. Hence we get $\omega \in\left(A_{m}+B_{m}\right)^{-1}(0)$ for every $m \in\{1,2, \ldots, N\}$. This completes the proof that $\omega \in \mathcal{F}$.

Suppose there is another subsequence $\left\{x_{n_{j}}\right\}$ of $\left\{x_{n}\right\}$ such that $x_{n_{j}} \rightarrow \omega^{\prime}$. Then we can show that $\omega^{\prime} \in \mathcal{F}$ in the same way. Assume $\omega \neq \omega^{\prime}$. Since $\lim _{n \rightarrow \infty}\left\|x_{n}-p\right\|$ exits for any $p \in \mathcal{F}$. Put $\lim _{n \rightarrow \infty}\left\|x_{n}-\omega\right\|=d$. Since the space satisfies Opial's condition, we see that

$$
\begin{aligned}
d & =\liminf _{i \rightarrow \infty}\left\|x_{n_{i}}-\omega\right\| \\
& <\liminf _{i \rightarrow \infty}\left\|x_{n_{i}}-\omega^{\prime}\right\| \\
& =\lim _{n \rightarrow \infty}\left\|x_{n}-\omega^{\prime}\right\| \\
& =\liminf _{j \rightarrow \infty}\left\|x_{n_{j}}-\omega^{\prime}\right\| \\
& <\liminf _{j \rightarrow \infty}\left\|x_{n_{j}}-\omega\right\|=d .
\end{aligned}
$$


This is a contradiction. This shows that $\omega=\omega^{\prime}$. This proves that the sequence $\left\{x_{n}\right\}$ converges weakly to $\omega \in \mathcal{F}$. This completes the proof.

If $N=2$, then we have the following.

Corollary 3.2 Let $C$ be a nonempty closed convex subset of H. Let $S: C \rightarrow C$ be an asymptotically strictly pseudocontractive mapping with the constant $\kappa$ and the sequence $\left\{k_{n}\right\}$. Let $A: C \rightarrow H$ be an inverse-strongly monotone mapping with the constant $\alpha$, and $B$ be a maximal monotone operator on $H$ such that the domain of $B$ is included in $C$. Assume $\mathcal{F}=(A+B)^{-1}(0) \cap F(S) \neq \emptyset$. Let $\left\{\alpha_{n, 1}\right\},\left\{\alpha_{n, 2}\right\}$, and $\left\{\beta_{n}\right\}$ be real number sequences in $(0,1)$. Let $\left\{r_{n}\right\}$ be a positive real number sequence. Let $\left\{x_{n}\right\}$ be a sequence in $C$ generated in the following iterative process:

$$
\left\{\begin{array}{l}
x_{1} \in C, \\
y_{n}=\beta_{n} x_{n}+\left(1-\beta_{n}\right) S^{n} x_{n}, \\
x_{n+1}=\alpha_{n, 1} y_{n}+\alpha_{n, 2} J_{r_{n}}\left(x_{n}-r_{n} A_{2} x_{n}\right), \quad n \geq 1,
\end{array}\right.
$$

where $J_{r_{n}}=\left(I+r_{n} B\right)^{-1}$ is the resolvent of $B$. Assume that the sequences $\left\{\alpha_{n, 1}\right\},\left\{\alpha_{n, 2}\right\},\left\{\beta_{n}\right\}$, $\left\{r_{n}\right\}$, and $\left\{k_{n}\right\}$ satisfy the following restrictions:

(a) $\sum_{m=1}^{2} \alpha_{n, m}=1$ and $0<a \leq \alpha_{n, m}<1, \forall m \in\{1,2\}$;

(b) $0 \leq \kappa \leq \beta_{n} \leq b<1$;

(c) $0<c \leq r_{n} \leq d<2 \alpha$;

(d) $\sum_{n=1}^{\infty}\left(k_{n}-1\right)<\infty$,

where $a, b, c$, and $d$ are positive real numbers. Then the sequence $\left\{x_{n}\right\}$ converges weakly to some point in $\mathcal{F}$.

If $S$ is asymptotically nonexpansive, then we find from Theorem 3.1 the following by letting $\beta_{n}=0$.

Corollary 3.3 Let $C$ be a nonempty closed convex subset of $H$. Let $N \geq 2$ be some positive integer and $S: C \rightarrow C$ be an asymptotically nonexpansive mapping with the sequence $\left\{k_{n}\right\}$. Let $A_{m}: C \rightarrow H$ be an inverse-strongly monotone mapping with the constant $\alpha_{m}$ and let $B_{m}$ be a maximal monotone operator on $H$ such that the domain of $B_{m}$ is included in $C$ for each $m \in\{2,3, \ldots, N\}$. Assume $\mathcal{F}=\bigcap_{m=2}^{N}\left(A_{m}+B_{m}\right)^{-1}(0) \cap F(S) \neq \emptyset$. Let $\left\{\alpha_{n, 1}\right\},\left\{\alpha_{n, 2}\right\}, \ldots,\left\{\alpha_{n, N}\right\}$, and $\left\{\beta_{n}\right\}$ be real number sequences in $(0,1)$. Let $\left\{r_{n, 2}\right\}, \ldots$, and $\left\{r_{n, N}\right\}$ be positive real number sequences. Let $\left\{x_{n}\right\}$ be a sequence in $C$ generated in the following iterative process:

$$
x_{1} \in C, \quad x_{n+1}=\alpha_{n, 1} S^{n} x_{n}+\sum_{m=2}^{N} \alpha_{n, m} J_{r_{n, m}}\left(x_{n}-r_{n, m} A_{m} x_{n}\right), \quad n \geq 1,
$$

where $J_{r_{n, m}}=\left(I+r_{n, m} B_{m}\right)^{-1}$ is the resolvent of $B_{m}$. Assume that the sequences $\left\{\alpha_{n, 1}\right\},\left\{\alpha_{n, 2}\right\}, \ldots$, $\left\{\alpha_{n, N}\right\},\left\{\beta_{n}\right\},\left\{r_{n, 2}\right\}, \ldots,\left\{r_{n, N}\right\}$, and $\left\{k_{n}\right\}$ satisfy the following restrictions:

(a) $\sum_{m=1}^{N} \alpha_{n, m}=1$ and $0<a \leq \alpha_{n, m}<1, \forall m \in\{2, \ldots, N\}$;

(b) $0<b \leq r_{n, m} \leq c<2 \alpha_{m}, \forall m \in\{2, \ldots, N\}$;

(c) $\sum_{n=1}^{\infty}\left(k_{n}-1\right)<\infty$,

where $a, b$ and $c$ are positive real numbers. Then the sequence $\left\{x_{n}\right\}$ converges weakly to some point in $\mathcal{F}$. 
If $S$ is the identity mapping, then we draw from Theorem 3.1 the following.

Corollary 3.4 Let $C$ be a nonempty closed convex subset of $H$. Let $N \geq 2$ be some positive integer. Let $A_{m}: C \rightarrow H$ be an inverse-strongly monotone mapping with the constant $\alpha_{m}$ and let $B_{m}$ be a maximal monotone operator on $H$ such that the domain of $B_{m}$ is included in $C$ for each $m \in\{2,3, \ldots, N\}$. Assume $\mathcal{F}=\bigcap_{m=2}^{N}\left(A_{m}+B_{m}\right)^{-1}(0) \neq \emptyset$. Let $\left\{\alpha_{n, 1}\right\},\left\{\alpha_{n, 2}\right\}, \ldots$, and $\left\{\alpha_{n, N}\right\}$ be real number sequences in $(0,1)$. Let $\left\{r_{n, 2}\right\}, \ldots$, and $\left\{r_{n, N}\right\}$ be positive real number sequences. Let $\left\{x_{n}\right\}$ be a sequence in $C$ generated in the following iterative process:

$$
x_{1} \in C, \quad x_{n+1}=\alpha_{n, 1} x_{n}+\sum_{m=2}^{N} \alpha_{n, m} J_{r_{n, m}}\left(x_{n}-r_{n, m} A_{m} x_{n}\right), \quad n \geq 1,
$$

where $J_{r_{n, m}}=\left(I+r_{n, m} B_{m}\right)^{-1}$ is the resolvent of $B_{m}$. Assume that the sequences $\left\{\alpha_{n, 1}\right\},\left\{\alpha_{n, 2}\right\}, \ldots$, $\left\{\alpha_{n, N}\right\},\left\{r_{n, 2}\right\}, \ldots$, and $\left\{r_{n, N}\right\}$ satisfy the following restrictions:

(a) $\sum_{m=1}^{N} \alpha_{n, m}=1$ and $0<a \leq \alpha_{n, m}<1, \forall m \in\{2, \ldots, N\}$;

(b) $0<b \leq r_{n, m} \leq c<2 \alpha_{m}, \forall m \in\{2, \ldots, N\}$,

where $a, b$, and $c$ are positive real numbers. Then the sequence $\left\{x_{n}\right\}$ converges weakly to some point in $\mathcal{F}$.

Let $f: H \rightarrow(-\infty, \infty]$ be a proper lower semicontinuous convex function. Define the subdifferential

$$
\partial f(x)=\{z \in H: f(x)+\langle y-x, z\rangle \leq f(y), \forall y \in H\}
$$

for all $x \in H$. Then $\partial f$ is a maximal monotone operator of $H$ into itself; see [38] for more details. Let $C$ be a nonempty closed convex subset of $H$ and $i_{C}$ be the indicator function of $C$, that is,

$$
i_{C} x= \begin{cases}0, & x \in C, \\ \infty, & x \notin C\end{cases}
$$

Furthermore, we define the normal cone $N_{C}(v)$ of $C$ at $v$ as follows:

$$
N_{C} v=\{z \in H:\langle z, y-v\rangle \leq 0, \forall y \in H\}
$$

for any $v \in C$. Then $i_{C}: H \rightarrow(-\infty, \infty]$ is a proper lower semicontinuous convex function on $H$ and $\partial i_{C}$ is a maximal monotone operator. Let $J_{r} x=\left(I+r \partial i_{C}\right)^{-1} x$ for any $r>0$ and $x \in H$. From $\partial i_{C} x=N_{C} x$ and $x \in C$, we get

$$
\begin{aligned}
v=J_{r} x & \Leftrightarrow \quad x \in v+r N_{C} v \\
& \Leftrightarrow \quad\langle x-v, y-v\rangle \leq 0, \quad \forall y \in C, \\
& \Leftrightarrow \quad v=P_{C} x,
\end{aligned}
$$

where $P_{C}$ is the metric projection from $H$ into $C$. Similarly, we can get that $x \in(A+$ $\left.\partial i_{C}\right)^{-1}(0) \Leftrightarrow x \in \operatorname{VI}(A, C)$. 
Corollary 3.5 Let $C$ be a nonempty closed convex subset of $H$. Let $N \geq 2$ be some positive integer and $S: C \rightarrow C$ be an asymptotically strictly pseudocontractive mapping with the constant $\kappa$ and the sequence $\left\{k_{n}\right\}$. Let $A_{m}: C \rightarrow H$ be an inverse-strongly monotone mapping with the constant $\alpha_{m}$ for each $m \in\{2,3, \ldots, N\}$. Assume $\mathcal{F}=\bigcap_{m=2}^{N} \operatorname{VI}\left(C, A_{m}\right) \cap$ $F(S) \neq \emptyset$. Let $\left\{\alpha_{n, 1}\right\},\left\{\alpha_{n, 2}\right\}, \ldots,\left\{\alpha_{n, N}\right\}$, and $\left\{\beta_{n}\right\}$ be real number sequences in $(0,1)$. Let $\left\{r_{n, 2}\right\}, \ldots$, and $\left\{r_{n, N}\right\}$ be positive real number sequences. Let $\left\{x_{n}\right\}$ be a sequence in $C$ generated in the following iterative process:

$$
\left\{\begin{array}{l}
x_{1} \in C, \\
y_{n}=\beta_{n} x_{n}+\left(1-\beta_{n}\right) S^{n} x_{n}, \\
x_{n+1}=\alpha_{n, 1} y_{n}+\sum_{m=2}^{N} \alpha_{n, m} P_{C}\left(x_{n}-r_{n, m} A_{m} x_{n}\right), \quad n \geq 1 .
\end{array}\right.
$$

Assume that the sequences $\left\{\alpha_{n, 1}\right\},\left\{\alpha_{n, 2}\right\}, \ldots,\left\{\alpha_{n, N}\right\},\left\{\beta_{n}\right\},\left\{r_{n, 2}\right\}, \ldots,\left\{r_{n, N}\right\}$, and $\left\{k_{n}\right\}$ satisfy the following restrictions:
(a) $\sum_{m=1}^{N} \alpha_{n, m}=1$ and $0<a \leq \alpha_{n, m}<1, \forall m \in\{2, \ldots, N\}$;
(b) $0 \leq \kappa \leq \beta_{n} \leq b<1$;
(c) $0<c \leq r_{n, m} \leq d<2 \alpha_{m}, \forall m \in\{2, \ldots, N\}$;
(d) $\sum_{n=1}^{\infty}\left(k_{n}-1\right)<\infty$,

where $a, b, c$, and $d$ are positive real numbers. Then the sequence $\left\{x_{n}\right\}$ converges weakly to some point in $\mathcal{F}$.

Proof Putting $B_{m}=\partial i_{C}$ for every $m \in\{2,3, \ldots, N\}$, we see $J_{r_{n, m}}=P_{C}$. We can immediately draw from Theorem 3.1 the desired conclusion.

If $S$ is the identity mapping, then we find from Corollary 3.5 the following.

Corollary 3.6 Let $C$ be a nonempty closed convex subset of $H$. Let $N \geq 2$ be some positive integer. Let $A_{m}: C \rightarrow H$ be an inverse-strongly monotone mapping with the constant $\alpha_{m}$ for each $m \in\{2,3, \ldots, N\}$. Assume $\mathcal{F}=\bigcap_{m=2}^{N} \operatorname{VI}\left(C, A_{m}\right) \neq \emptyset$. Let $\left\{\alpha_{n, 1}\right\},\left\{\alpha_{n, 2}\right\}, \ldots$, and $\left\{\alpha_{n, N}\right\}$ be real number sequences in $(0,1)$. Let $\left\{r_{n, 2}\right\}, \ldots$, and $\left\{r_{n, N}\right\}$ be positive real number sequences. Let $\left\{x_{n}\right\}$ be a sequence in $C$ generated in the following iterative process:

$$
x_{1} \in C, \quad x_{n+1}=\alpha_{n, 1} x_{n}+\sum_{m=2}^{N} \alpha_{n, m} P_{C}\left(x_{n}-r_{n, m} A_{m} x_{n}\right), \quad n \geq 1 .
$$

Assume that the sequences $\left\{\alpha_{n, 1}\right\},\left\{\alpha_{n, 2}\right\}, \ldots,\left\{\alpha_{n, N}\right\},\left\{\beta_{n}\right\},\left\{r_{n, 2}\right\}, \ldots,\left\{r_{n, N}\right\}$, and $\left\{k_{n}\right\}$ satisfy the following restrictions:

(a) $\sum_{m=1}^{N} \alpha_{n, m}=1$ and $0<a \leq \alpha_{n, m}<1, \forall m \in\{2, \ldots, N\}$;

(b) $0<b \leq r_{n, m} \leq c<2 \alpha_{m}, \forall m \in\{2, \ldots, N\}$;

(c) $\sum_{n=1}^{\infty}\left(k_{n}-1\right)<\infty$,

where $a, b$, and $c$ are positive real numbers. Then the sequence $\left\{x_{n}\right\}$ converges weakly to some point in $\mathcal{F}$. 
Authors' contributions

All authors contributed equally and significantly in writing this paper. All authors read and approved the final manuscript.

\section{Author details}

'Department of Mathematics, Gyeongsang National University, Jinju, 660-701, Korea. ${ }^{2}$ School of Mathematics and Information Science, Henan Polytechnic University, Jiaozuo, 454000, China. ${ }^{3}$ Department of Mathematics and RINS, Gyeongsang National University, Jinju, 660-701, Korea.

\section{Acknowledgements}

The authors are grateful to the editor and the reviewers' suggestions which improved the contents of the article.

Received: 17 October 2012 Accepted: 9 February 2013 Published: 22 April 2013

\section{References}

1. Manro, S, Kumar, S, Bhatia, SS: Common fixed point theorems in intuitionistic fuzzy metric spaces using occasionally weakly compatible maps. J. Math. Comput. Sci. 2, 73-81 (2012)

2. Yang, S, Li, W: Iterative solutions of a system of equilibrium problems in Hilbert spaces. Adv. Fixed Point Theory 1 , $15-26(2011)$

3. Qin, X, Cho, SY, Kang, SM: On hybrid projection methods for asymptotically quasi- $\boldsymbol{\phi}$-nonexpansive mappings. Appl. Math. Comput. 215, 3874-3883 (2010)

4. Zegeye, $\mathrm{H}$, Shahzad, N: Strong convergence theorem for a common point of solution of variational inequality and fixed point problem. Adv. Fixed Point Theory 2, 374-397 (2012)

5. Cho, SY, Qin, X, Kang, SM: Hybrid projection algorithms for treating common fixed points of a family of demicontinuous pseudocontractions. Appl. Math. Lett. 25, 854-857 (2012)

6. Luo, H, Wang, Y: Iterative approximation for the common solutions of a infinite variational inequality system for inverse-strongly accretive mappings. J. Math. Comput. Sci. 2, 1660-1670 (2012)

7. Cho, SY, Qin, X, Kang, SM: Hybrid projection algorithms for treating common fixed points of a family of demicontinuous pseudocontractions. Appl. Math. Lett. 25, 854-857 (2012)

8. Byrne, C: A unified treatment of some iterative algorithms in signal processing and image reconstruction. Inverse Probl. 20, 103-120 (2008)

9. Tiwari, R, Shukla, DP: Coincidence points and common fixed points in cone Banach spaces. J. Math. Comput. Sci. 2, 1464-1474 (2012)

10. Qin, X, Shang, M, Su, Y: Strong convergence of a general iterative algorithm for equilibrium problems and variational inequality problems. Math. Comput. Model. 48, 1033-1046 (2008)

11. Lv, S, Wu, C: Convergence of iterative algorithms for a generalized variational inequality and a nonexpansive mapping. Eng. Math. Lett. 1, 44-57 (2012)

12. Cho, SY, Kang, SM: Approximation of common solutions of variational inequalities via strict pseudocontractions. Acta Math. Sci. 32, 1607-1618 (2012)

13. Qin, $\mathrm{X}, \mathrm{Cho}, \mathrm{YJ}$, Kang, SM, Zhou, H: Convergence of a modified Halpern-type iteration algorithm for quasi- $\boldsymbol{\phi}$-nonexpansive mappings. Appl. Math. Lett. 22, 1051-1055 (2009)

14. Cho, YJ, Petrot, N: Regularization and iterative method for general variational inequality problem in Hilbert spaces. J. Inequal. Appl. 2011, 21 (2011)

15. Qin, X, Cho, SY, Kang, SM: Strong convergence of shrinking projection methods for quasi- $\boldsymbol{\phi}$-nonexpansive mappings and equilibrium problems. J. Comput. Appl. Math. 234, 750-760 (2010)

16. Lin, LJ, Huang, YJ: Generalized vector quasi-equilibrium problems with applications to common fixed point theorems and optimization problems. Nonlinear Anal. 66, 1275-1289 (2007)

17. Cho, YJ, Kang, SM, Zhou, H: Approximate proximal point algorithms for finding zeroes of maximal monotone operators in Hilbert spaces. J. Inequal. Appl. 2008, 598191 (2008)

18. Qin, X, Cho, YJ, Kang, SM: Approximating zeros of monotone operators by proximal point algorithms. J. Glob. Optim. 46, 75-87 (2010)

19. Kammura, S, Takahashi, W: Approximating solutions of maximal monotone operators in Hilbert spaces. J. Approx Theory 106, 226-240 (2000)

20. Aoyama, K, Kimura, Y, Takahashi, W, Toyoda, M: On a strongly nonexpansive sequence in Hilbert spaces. J. Nonlinear Convex Anal. 8, 471-489 (2007)

21. Takahashi, S, Takahashi, W, Toyoda, M: Strong convergence theorems for maximal monotone operators with nonlinear mappings in Hilbert spaces. J. Optim. Theory Appl. 147, 27-41 (2010)

22. Qin, X, Su, Y: Approximation of a zero point of accretive operator in Banach spaces. J. Math. Anal. Appl. 329, 415-424 (2007)

23. Eshita, K, Takahashi, W: Approximating zero points of accretive operators in general Banach spaces. Fixed Point Theory Appl. 2, 105-116 (2007)

24. Qin, X, Cho, YJ, Kang, SM: Approximating zeros of monotone operators by proximal point algorithms. J. Glob. Optim. 46, 75-87 (2010)

25. Hao, Y: On variational inclusion and common fixed point problems in Hilbert spaces with applications. Appl. Math. Comput. 217, 3000-3010 (2010)

26. Min, L, Shisheng, Z: A new iterative method for finding common solutions of generalized equilibrium problem, fixed point problem of infinite $k$-strict pseudo-contractive mappings, and quasi-variational inclusion problem. Acta Math Sci. 32, 499-519 (2012)

27. Zhang, SS, Lee, JHW, Chan, CK: Algorithms of common solutions to quasi variational inclusion and fixed point problems. Appl. Math. Mech. 29, 571-581 (2008)

28. Takahahsi, W, Toyoda, M: Weak convergence theorems for nonexpansive mappings and monotone mappings. J. Optim. Theory Appl. 118, 417-428 (2003)

29. Tada, A, Takahashi, W: Weak and strong convergence theorems for a nonexpansive mappings and an equilibrium problem. J. Optim. Theory Appl. 133, 359-370 (2007) 
30. Manaka, H, Takahashi, W: Weak convergence theorems for maximal monotone operators with nonspreading mappings in a Hilberts space. CUBO 13,11-24 (2011)

31. Qin, X, Cho, YJ, Kang, SM: Convergence theorems of common elements for equilibrium problems and fixed point problems in Banach spaces. J. Comput. Appl. Math. 225, 20-30 (2009)

32. Qin, X, Chang, SS, Cho, YJ: Iterative methods for generalized equilibrium problems and fixed point problems with applications. Nonlinear Anal. 11, 2963-2972 (2010)

33. Kim, JK: Strong convergence theorems by hybrid projection methods for equilibrium problems and fixed point problems of the asymptotically quasi- $\phi$-nonexpansive mappings. Fixed Point Theory Appl. 2011, 10 (2011)

34. Opial, Z: Weak convergence of the sequence of successive approximations for nonexpansive mappings. Bull. Am. Math. Soc. 73, 591-597 (1967)

35. Tan, KK, Xu, HK: Approximating fixed points of nonexpansive mappings by the Ishikawa iteration process. J. Math. Anal. Appl. 178, 301-308 (1993)

36. Sahu, DR, Xu, HK, Yao, JC: Asymptotically strict pseudocontractive mappings in the intermediate sense. Nonlinear Anal. 70, 3502-3511 (2009)

37. Hao, Y, Cho, SY, Qin, X: Some weak convergence theorems for a family of asymptotically nonexpansive nonself mappings. Fixed Point Theory Appl. 2010, Article ID 218573 (2010)

38. Rockafellar, RT: Monotone operators and the proximal point algorithm. SIAM J. Control Optim. 14, $877-898$ (1976)

doi:10.1186/1029-242X-2013-199

Cite this article as: Cho et al.: Convergence analysis of an iterative algorithm for monotone operators. Journal of Inequalities and Applications 2013 2013:199.

\section{Submit your manuscript to a SpringerOpen ${ }^{\circ}$ journal and benefit from:}

- Convenient online submission

- Rigorous peer review

- Immediate publication on acceptance

Open access: articles freely available online

- High visibility within the field

- Retaining the copyright to your article 